\title{
Auxin-inducible protein depletion system in fission yeast
}

\author{
Mai Kanke ${ }^{1}$, Kohei Nishimura ${ }^{1,2}$, Masato Kanemaki ${ }^{1,2}$, Tatsuo Kakimoto ${ }^{1}$, Tatsuro S Takahashi ${ }^{1}$, Takuro Nakagawa', \\ Hisao Masukata ${ }^{1 *}$
}

\begin{abstract}
Background: Inducible inactivation of a protein is a powerful approach for analysis of its function within cells. Fission yeast is a useful model for studying the fundamental mechanisms such as chromosome maintenance and cell cycle. However, previously published strategies for protein-depletion are successful only for some proteins in some specific conditions and still do not achieve efficient depletion to cause acute phenotypes such as immediate cell cycle arrest. The aim of this work was to construct a useful and powerful protein-depletion system in Shizosaccaromyces pombe.

Results: We constructed an auxin-inducible degron (AID) system, which utilizes auxin-dependent polyubiquitination of Aux/IAA proteins by SCF ${ }^{T R 1}$ in plants, in fission yeast. Although expression of a plant F-box protein, TIR1, decreased Mcm4-aid, a component of the MCM complex essential for DNA replication tagged with Aux/IAA peptide, depletion did not result in an evident growth defect. We successfully improved degradation efficiency of Mcm4-aid by fusion of TIR1 with fission yeast Skp1, a conserved F-box-interacting component of SCF (improved-AID system; i-AID), and the cells showed severe defect in growth. The $i$-AID system induced degradation of Mcm4-aid in the chromatin-bound MCM complex as well as those in soluble fractions. The $i$-AID system in conjunction with transcription repression (off-AID system), we achieved more efficient depletion of other proteins including Pol1 and Cdc45, causing early S phase arrest.
\end{abstract}

Conclusion: Improvement of the AID system allowed us to construct conditional null mutants of S. pombe. We propose that the off-AID system is the powerful method for in vivo protein-depletion in fission yeast.

\section{Background}

Schizosaccharomyces pombe is a widely used model organism for analysis of important cellular functions [1-3]. The use of conditional inactivation by mutations or depletion of proteins in vivo has been used successfully for analysis of gene functions. A conditional protein degradation system, so-called "degron", which depletes proteins from cells, is a powerful tool for analyzing the "null" phenotype of various genes. In budding yeast, a heat-inducible degron (ts-degron) system has been devised $[4,5]$ and used for studies of essential gene functions [6,7]. In fission yeast, the ts-degron mutant of Bir1, a nuclear protein involved in mitotic segregation, has been reported to cause destruction of the protein, resulting in growth defects at

\footnotetext{
* Correspondence: masukata@bio.sci.osaka-u.ac.jp

'Graduate School of Science, Osaka University, 1-1 Machikaneyama-cho,

Toyonaka, Osaka 560-0043, Japan

Full list of author information is available at the end of the article
}

restrictive temperature [8]. For functional analysis, however, as this system is unable to deplete proteins sufficiently to arrest the cell cycle, it is often combined with $t s$ alleles of the genes of interest $[9,10]$.

Recently, an auxin-inducible degron (AID) system was developed for use in budding yeast and higher eukaryotic cells [11]. This strategy involves a plant-specific mechanism that relies on response to the plant hormone auxin and a conserved poly-ubiquitination pathway involving the E3 ubiquitin ligase, SCF ( $\mathrm{S} k p 1$, Cullin and F-box protein) complex $[12,13]$. In plant cells, auxin binds to transport inhibitor response 1 (TIR1) protein $[14,15]$ and promotes binding of the SCF ${ }^{\mathrm{TIR} 1}$, a form of SCF containing TIR1, to Aux/IAA transcription repressors [16-18]. The Aux/IAA proteins are poly-ubiquitinated by the $\mathrm{SCF}^{\mathrm{TIR} 1}$ and then degraded by proteasomes [19]. Except for the auxin-dependent recognition of Aux/IAA proteins by TIR1, components of the SCF and
C Biomed Central

() 2011 Kanke et al; licensee BioMed Central Ltd. This is an Open Access article distributed under the terms of the Creative Commons Attribution License (http://creativecommons.org/licenses/by/2.0), which permits unrestricted use, distribution, and reproduction in any medium, provided the original work is properly cited. 
ubiquitin-proteasome pathway, especially F-box interacting protein skp1, are conserved among eukaryotes. This makes it possible to form the SCF ${ }^{\mathrm{TIR} 1}$ in non-plant cells by expression of TIR1 and to degrade Aux/IAA-tagged proteins depending on addition of auxin.

We have constructed an AID system for use in $S$. pombe by expressing TIR1. Although Mcm4 protein fused with Aux/IAA peptide (aid-tag) at the C-terminus (Mcm4-aid) was decreased upon addition of auxin, the strain did not show any obvious growth defect because of inefficient depletion. Here we describe an improved form of the AID system. Depletion of Mcm4-aid protein was greatly enhanced by expression of Skp1-TIR1, a fusion protein comprising plant TIR1 and fission yeast Skp1. This $i$-AID system (improved AID system) was applicable for depletion of other essential replication proteins including Orc2, Cdc45 and Pol1. Furthermore, in conjunction of the $i$-AID system with transcription repression (off-AID system), Cdc45- or Pol1-depleted cells showed severe replication defects resulting in cell cycle arrest. The off-AID system involving two-step gene modifications will be a powerful tool for analyzing the function of essential genes under null conditions in $S$. pombe.

\section{Results}

\section{Auxin-dependent degradation of Mcm4-aid in fission yeast}

To develop an auxin-inducible protein degradation system in fission yeast, we constructed a strain that expresses Arabidopsis thaliana TIR1 (AtTIR1), a plant specific F-box protein that binds auxin, from the chromosome. We placed the AtTIR1 gene under control of the $n m t 41\left(P_{n m t 41}\right)$ promoter to induce gene expression in the absence of thiamine [20,21]. As a target of degradation, we used Mcm4, a component of the MCM complex, which is required throughout the whole process of chromosomal DNA replication. The mcm4-aid, tagged with full-length IAA17 (229-amino acid peptides) at the C-terminus of the $m c m 4^{+}$gene on the chromosome, grew as well as the wild-type strain without the aid-tag (data not shown). The level of Mcm4-aid protein analyzed by immunoblotting with anti-Mcm4 antibody was similar to that in the untagged strain (data not shown). Upon addition of a synthetic auxin, NAA (1-naphthaleneacetic acid), to log-phase cells expressing AtTIR1, the protein level of Mcm4-aid decreased in $1 \mathrm{~h}$ (Figure 1A). The amount of protein at $2 \mathrm{~h}$ was estimated to be about $25 \%$ of that without auxin (Figure 1B). To examine whether reduction of $\mathrm{Mcm} 4$-aid protein affects DNA replication and cell growth, the DNA content was analyzed by flow cytometry (Figure $1 \mathrm{C}$ ). In the absence of auxin, mcm4-aid cells retained a 2C DNA content, because fission yeast cells have a long G2 phase and cytokinesis occurs in S phase (Figure $1 C$, left panel). In contrast, upon addition of auxin, cells with less than a $2 \mathrm{C}$ DNA content appeared at 2-4 h (Figure $1 \mathrm{C}$, right panel), suggesting that a decrease in $\mathrm{Mcm} 4$-aid protein retarded DNA replication. However, these cells did not exhibit a severe growth defect on the auxin-containing medium (Figure 1D). These results show that, although the AID system degrades Mcm4-aid protein in fission yeast, more efficient depletion of the target protein is required for physiological analysis.

\section{NLS and Skp1-fusion to AtTIR1 enhances the efficiency of the AID system}

We considered two possible reasons for the insufficient depletion of Mcm4-aid protein. First, the concentration of AtTIR1 imported to the nucleus may not be sufficient to promote efficient degradation, since the MCM complex exists throughout the cell cycle. If this is the case, addition of nuclear localization signals (NLSs) to AtTIR1 should increase the efficiency of degradation. Second, the plant AtTIR1 may fail to interact strongly with the $S$. pombe SCF components. This problem could be overcome by fusion of AtTIR1 with fission yeast Skp1, a conserved F-box-interacting protein [22] (Figure 2A). The pREP41 plasmid carrying AtTIR1-NLS or Skp1-AtTIR1 was introduced into the mcm4-aid strain, and the growth of the cells was examined on plates containing auxin. Cells expressing AtTIR1-NLS grew more slowly than those expressing AtTIR1 in the presence of auxin (Figure 2B). Cells harboring Skp1-AtTIR1 exhibited severe growth defects on the auxin plate (Figure $2 \mathrm{~B}$ ). These results suggest that the inefficient degradation of Mcm4-aid protein was mainly due to inefficient formation of the SCF ${ }^{\mathrm{TIR} 1}$ complex in fission yeast. Therefore, we used a strain carrying a single copy of skp1-AtTIR1$N L S$ fusion gene (Figure $2 \mathrm{C}$ ) inserted into the genome in the following experiments.

\section{Optimizing the expression of Skp1-AtTIR1-NLS from the genomic locus}

During the course of improving the AID system, we found that the expression level of TIR1 was crucial for efficient depletion of Mcm4-aid protein. The strain carrying $P_{n m t 41}-s k p 1-A t T I R 1-N L S$ integrated at the ade $^{+}$ locus on the chromosome did not show marked growth defects on auxin plates, unlike the results obtained with the strain harboring $P_{n m t 41}$-skp1-AtTIR1 on a multicopy plasmid (Figure 3A). Immunoblotting revealed that the degree of Skp1-AtTIR1-NLS expression from the $P_{n m t 41}$ promoter on the chromosome was about half that of Skp1-AtTIR1 expressed on the plasmid (Figure 3B), suggesting that a certain level of TIR1 expression is required for efficient degradation. Comparison of TIR1 expression from different promoters showed that the 


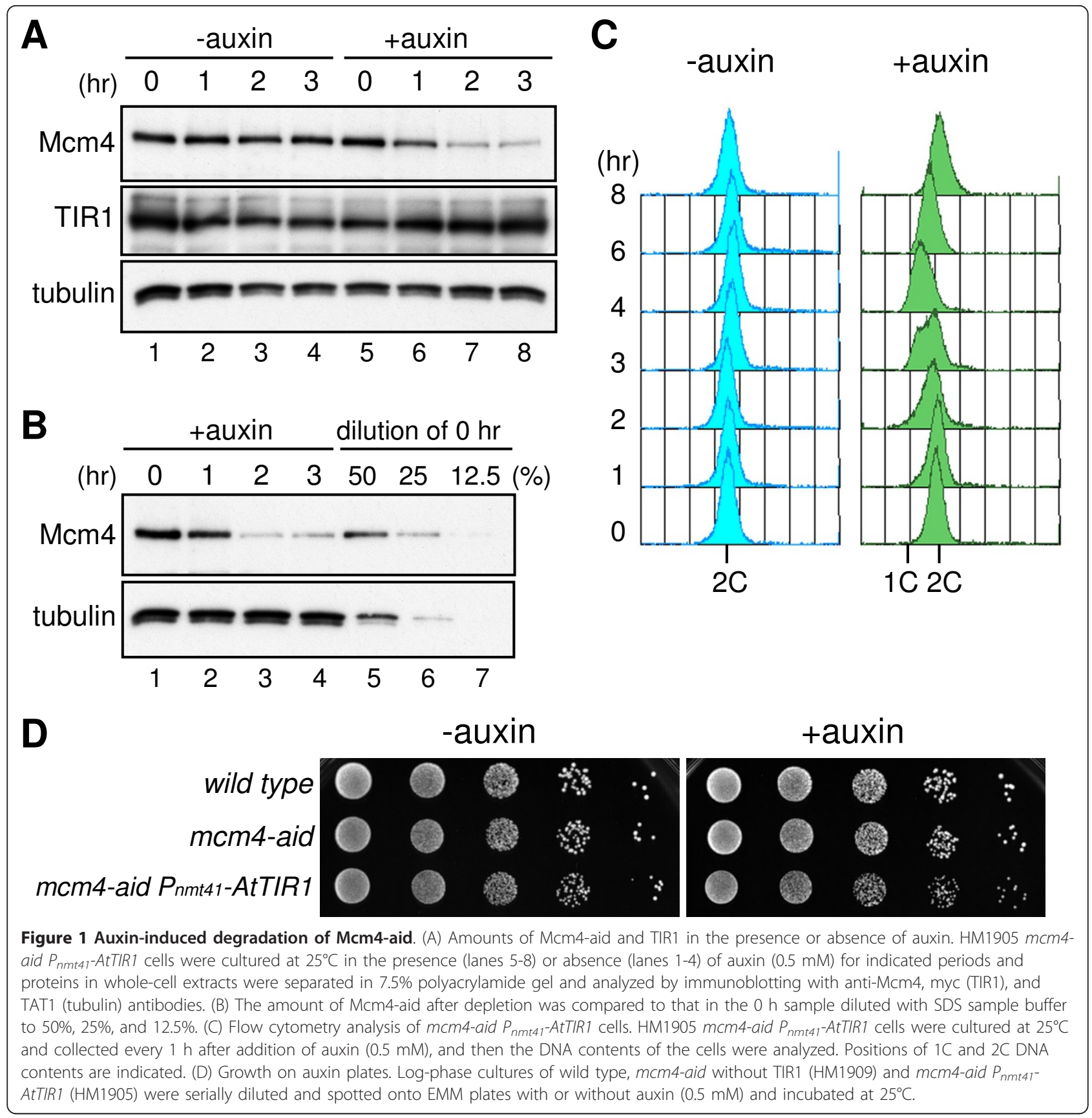

amount of Skp1-AtTIR1-NLS expressed under control of the adh15 promoter $\left(P_{a d h 15}\right)$, a weak derivative of the adh1 promoter [23], was similar to that of Skp1-AtTIR1 expressed from the $P_{n m t 41}$ promoter on the plasmid, while the expression form $P_{a d h 81}$, a much weaker derivative of $P_{a d h 1}$ [24] was less than that from $P_{n m t 41}$ (Figure 3B). The $P_{\text {adh15-skp1-AtTIR1-NLS mcm4-aid }}$ strain showed markedly defective growth on auxin-containing plates, whereas the $P_{a d h 81}$ derivative did not (Figure 3A). However, a further increase in TIR concentration, such as that achieved under control of the nmt1 or $a d h 1$ promoter, led to inhibition of cell growth even in the absence of the aid-tag and auxin (data not shown). We did not observe inhibition in specific cellcycle phase. Therefore, the cellular concentration of TIR1 is important for efficient depletion of the target protein as has been observed in plant cells [14,25].

To examine how efficiently Mcm4-aid protein was degraded in the $P_{\text {adh15-skp1-AtTIR1-NLS mcm4-aid }}$ strain, the amount of Mcm4-aid in cell extracts prepared from log-phase cells in the presence or absence of auxin was analyzed by immunoblotting. The amount of 


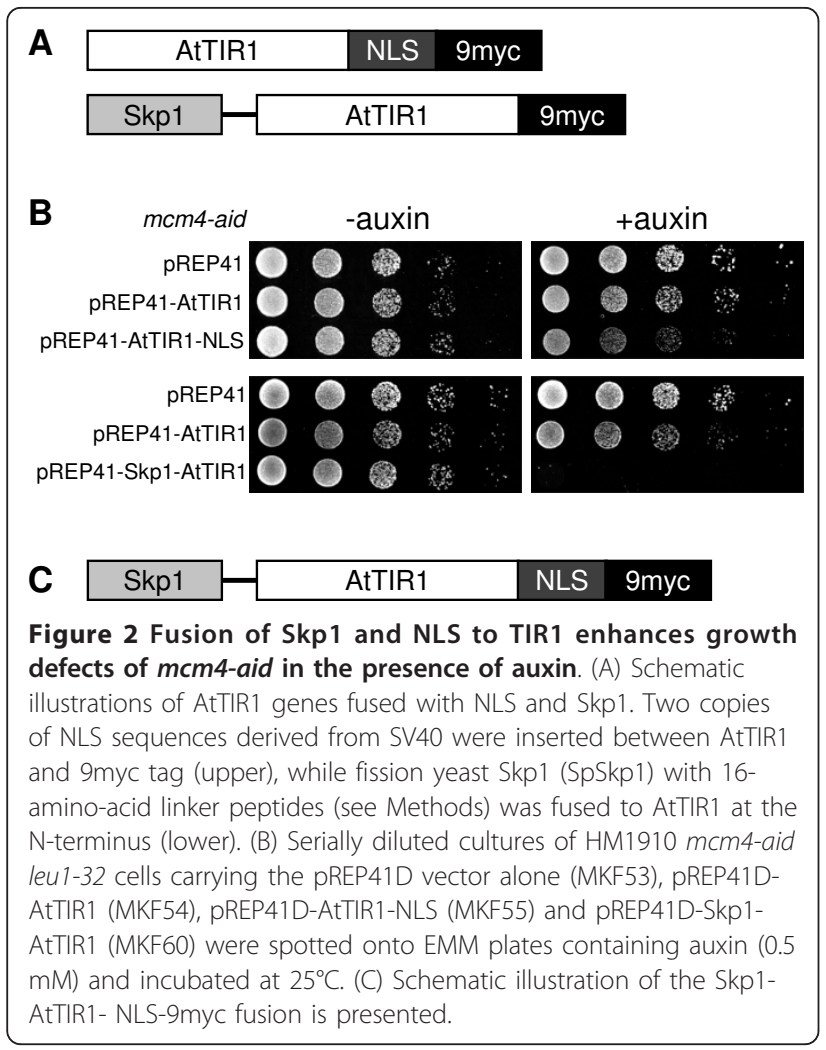

Mcm4-aid protein decreased rapidly within $1 \mathrm{~h}$ to below $12.5 \%$ of the original amount (Figure $3 \mathrm{C}$ and $3 \mathrm{D}$ ). The decrease was detected as early as 20 min after addition of auxin (Figure 3E). Under such conditions, a sharp 1C DNA peak appeared and was still evident at $8 \mathrm{~h}$ after addition of auxin (Figure 3F). The cell number did not increase after one cell division (Figure 3G) and cells were arrested with elongated shape containing a single nucleus (data not shown). These results show that the improved AID ( $i$-AID) system depleted Mcm4-aid protein to cause tight cell cycle arrest at early $S$ phase.

\section{Degradation of Mcm4-aid protein in the chromatin-bound MCM complex}

Next, we investigated whether the $i$-AID system promotes degradation of Mcm4-aid protein in the chromatin-bound MCM complex. Cells expressing Mcm4-aid and Skp1-AtTIR1-NLS were synchronized at the G2/M boundary by $c d c 25-22$ mutation [26] and released in the presence of hydroxyurea, $\mathrm{HU}$, which allows replication to initiate but retards fork progression due to depletion of deoxynucleotide pools (Figure 4A). The cells were then incubated for $1 \mathrm{~h}$ with auxin, and the amount of Mcm4aid protein was analyzed by immunoblotting. The amount of Mcm4-aid was greatly decreased in cells treated with auxin (Figure 4B, HU3h+A, lane 4), relative to that in the absence of auxin (HU3h-A, lane 3). These results indicate that most of the $\mathrm{Mcm} 4$-aid protein was efficiently degraded in the HU-arrested cells. The band showing decreased mobility (as indicated by an asterisk in lane 2 of Figure 4B) at $2 \mathrm{~h}$ in the presence of $\mathrm{HU}$ was probably a form of Mcm4-aid protein phosphorylated by DDK, CDK or checkpoint kinases activated in the presence of HU [27-29]. We were concerned whether the $i$ AID system decreased the amounts of other subunits of the MCM complex in addition to Mcm4-aid protein. However, the amounts of these subunits did not change significantly in the presence of auxin (Figure 4B). It has been shown that the individual subunits of the MCM complex exists in similar amounts [30], and that the majority form heteromeric hexamers in fission yeast cells [31]. Taking these observations together with our present results, it is likely that Mcm4-aid protein is selectively degraded, leaving the other subunits undegraded.

If Mcm4-aid is degraded in the chromatin-associated MCM complex, the other subunits may not remain on the chromatin. To examine whether the other MCM subunits were released upon degradation of Mcm4-aid protein, we carried out a chromatin immnoprecipitation (ChIP) assay using anti-Mcm6 antibody. Two sets of primers amplifying the ars2004 locus, an efficient replication origin [32], and a non-ARS1 locus, $30 \mathrm{~kb}$ distant from the origin, were used for real-time PCR to measure the relative amounts of precipitated DNA (Figure 4C). In HU-arrested cells without auxin (HU2h, HU3h-A), Mcm6 was enriched at ars2004 in comparison with non-ARS1, while no significant localization was observed in G2-arrested cells (G2) (Figure 4C), as shown in a previous study [33]. Upon addition of auxin, IP recovery of ars 2004 was decreased markedly to a level similar to that of non-ARS1 (Figure 4C, HU3h+A). These results indicate that $\mathrm{Mcm} 4$ is required for maintenance of the other MCM subunits on the chromatin. From these results, we concluded that the $i$-AID system induced efficient degradation of Mcm4-aid in the chromatin-bound MCM complex.

As the MCM complex is essential for progression of the replication fork, dissociation of the MCM complex will arrest DNA replication. To confirm this, we used flow cytometry to analyze the recovery of DNA replication upon removal of $\mathrm{HU}$ (Figure 4D). In the absence of auxin, DNA replication readily resumed after removal of $\mathrm{HU}$, as DNA the content increased from $1 \mathrm{C}$ to $2 \mathrm{C}$ in 0 90 min (Figure 4D, left panel). In contrast, the DNA content of cells treated with auxin remained at $1 \mathrm{C}$ even at $120 \mathrm{~min}$ after removal of $\mathrm{HU}$ (Figure 4D, right panel), indicating that depletion of Mcm4 prevented progression of the replication fork. This is consistent with the above conclusion that Mcm4 in the chromatin-bound MCM complex is efficiently depleted by the $i$-AID system. 


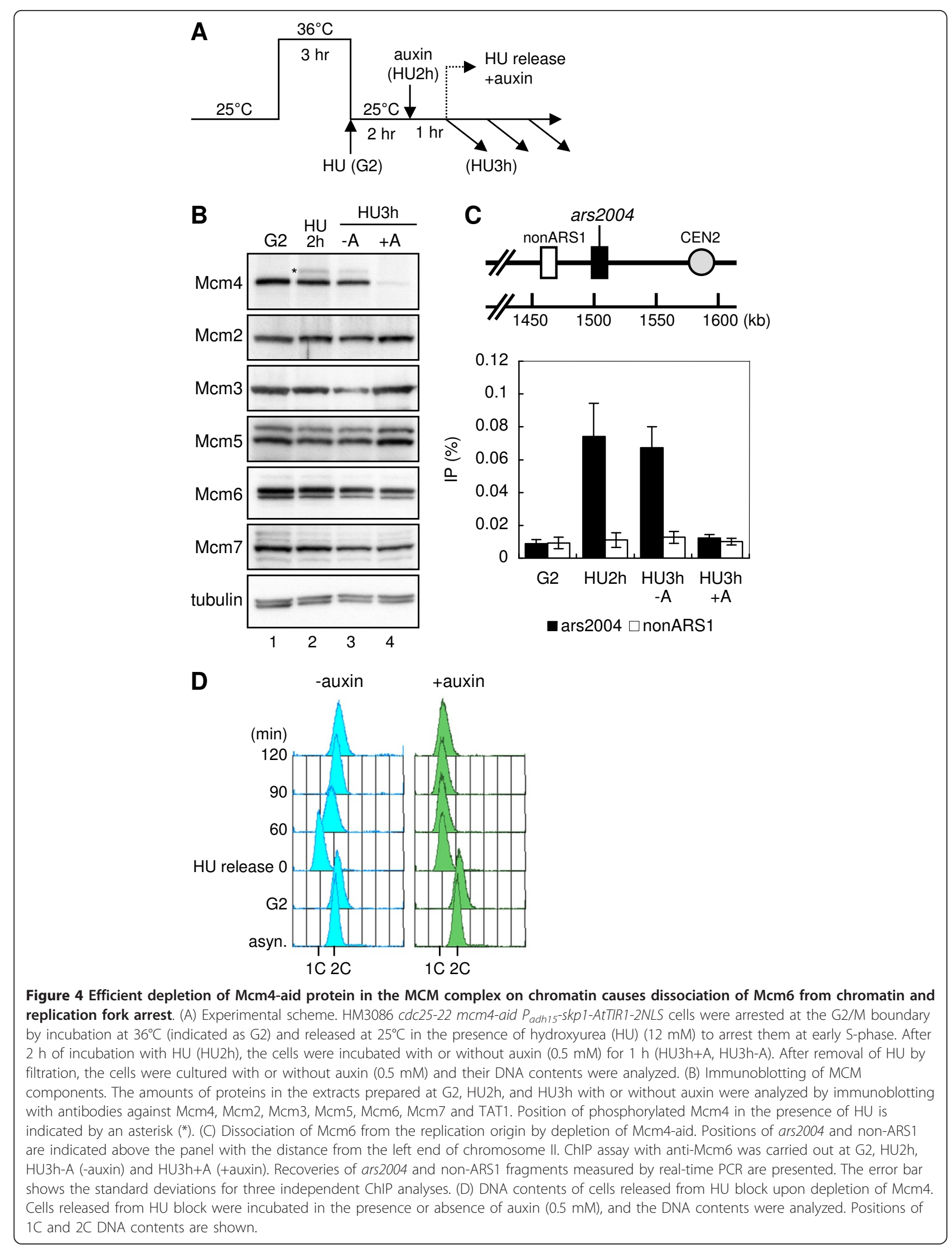




\section{Application of the $i$-AID system for depletion of other essential proteins in fission yeast}

In order to examine whether the $i$-AID system is applicable for depletion of other proteins in fission yeast, we constructed strains expressing various essential factors fused with the aid-tag at the C-terminus. The factors examined were Orc2, Orc4 and Orc6, components of the origin recognition complex (ORC), Cdc45, Mcm10, Psf1, a subunit of GINS, Cdc20 and Dpb2, the catalytic and the second largest subunits of DNA Pole, Pol1, Pol12 and Spp2, the catalytic, the second largest and the primase subunits of DNA Pol $\alpha$, Hsk1, the catalytic subunit of DDK, Ssl3, a subunit of cohesin loader, and Cia1/Asf1, a histone chaperone. The effects of the $i$-AID system were evaluated in terms of growth on auxin-containing plates and DNA content analyzed by flow cytometry. Growth of the orc2-i-aid strain was severely retarded on the auxin plate and orc6-i-aid and $c d c 45-i$ aid strains showed slow growth. On the other hand, no significant growth retardation was observed for strains cdc20-i-aid, pol1-i-aid and mcm10-i-aid (Figure 5A and Table 1). The results of flow cytometry showed that DNA replication was retarded in orc2-i-aid, $c d c 45$ - $i$-aid and $c d c 20$-i-aid, and slightly delayed in orc6-i-aid and pol1-i-aid, whereas no significant defect was observed for $m c m 10$ - $i$-aid (Figure 5B and Table 1). Strains orc4- $i$ aid, psf1-i-aid, pol12-i-aid, spp2-i-aid and dpb2-aid also showed defective growth on auxin plates, whereas hsk1-i-aid, ssl3-i-aid and cia1-i-aid showed no defect (Table 1). We examined whether the $i$-AID system affected the amount of Mcm10-aid protein, because the above assays had indicated no apparent defect for strain mcm10-i-aid. The results of immunoblotting with antiMcm10 antibody showed that the amount of Mcm10aid protein decreased to less than $25 \%$ of the original amount within $1 \mathrm{~h}$ after addition of auxin (Figure $5 \mathrm{C}$ ), demonstrating that the $i$-AID system induced degradation of Mcm10-aid protein. Auxin-induced decrease in the tagged protein was also observed in ssl3-i-aid and cia1-i-aid strains (data not shown). Although the $i$-AID system can induce degradation of various proteins in fission yeast, further efficient depletion, which results in tight arrest of the cell cycle, will be required to analyze the functions of proteins at the molecular level.

\section{Efficient depletion of replication proteins by the off-AID system causes tight cell-cycle arrest}

Although the $i$-AID system promoted rapid degradation of various target proteins, significant amounts of protein remained after depletion (Figure $5 \mathrm{C}$ and data not shown), probably due to de novo protein synthesis. In order to decrease the target protein further, we combined the $i$-AID system with transcriptional repression (off-AID system). To achieve this, the pol1-aid and cdc45-aid genes were placed under the control of the thiamine-repressible $P_{n m t 81}$ promoter. In addition, both AtTIR1 and Oryza sativa TIR1 (OsTIR1), which induces more efficient degradation than AtTIR1 in budding yeast [11], were expressed from constitutive $P_{\text {adh15 }}$ promoters (double-TIR1). Thiamine was added to shut off the transcription of the pol1-aid or cdc45-aid gene, and then auxin was added during cell cycle arrest at the G2/ $\mathrm{M}$ boundary using $c d c 25-22$ mutation (Figure 6A). Upon release from $\mathrm{G} 2 / \mathrm{M}$ at $1 \mathrm{~h}$ after addition of auxin, the amounts of Pol1-aid and Cdc45-aid proteins were greatly decreased to nearly undetectable levels (Figure 6B). The results of flow cytometry showed that pol1-off-aid and cdc45-off-aid cells were arrested with a $1 C$ DNA content, indicating severe defects in the early stage of DNA replication (Figure 6C). The off-AID system promoted strong growth defect on auxin plates for almost all the strains tested including mcm10-off-aid, hsk1-off-aid, ssl3-off-aid, and cia1-off-aid, which did not show significant defect with the $i$-AID system (Table 1). These results suggest that the off-AID system consisting of the $i$-AID combined with promoter shut-off of the target gene is widely applicable for efficient depletion of proteins in fission yeast cells.

\section{Discussion}

We have developed a powerful protein depletion system, "off-AID", in fission yeast by combining transcription repression with auxin-dependent protein degradation. An initial attempt that involved expression of TIR1 in strain mcm4-aid showed only a marginal defect on cell growth in the presence of auxin. However, the $i$-AID system consisting of TIR1 fused with fission yeast Skp1 markedly increased the efficiency of Mcm4-aid protein degradation, causing severe replication defect and cell cycle arrest. This suggested that the interaction between plant TIR1 and fission yeast Skp1 might be rate-limiting for SCF ${ }^{\text {TIR1 }}$ assembly. We also showed that the level of TIR1 expression is crucial for efficient depletion of Mcm4-aid protein as observed in plant cells [14,25]. Expression of Skp1-TIR1-NLS from the adh15 promoter resulted in severely defective growth on an auxin plate, whereas a reduced cellular concentration of Skp1-TIR1NLS expressed from the nmt41 promoter did not result in the same phenotype (Figure 3). We noticed that the NAA concentration is also important for the AID system in fission yeast. The mcm4-i-aid strain did not show growth defect at $0.1 \mathrm{mM}$ NAA, whereas NAA concentration higher than $1 \mathrm{mM}$ affected the growth of untagged strain (data not shown). Since auxin may act as a signaling molecule to promote morphogenesis in budding yeast [34], a similar pathway may present in fission yeast. The $i$-AID system decreased the level of Mcm4-aid protein to about $10 \%$ of the original amount 


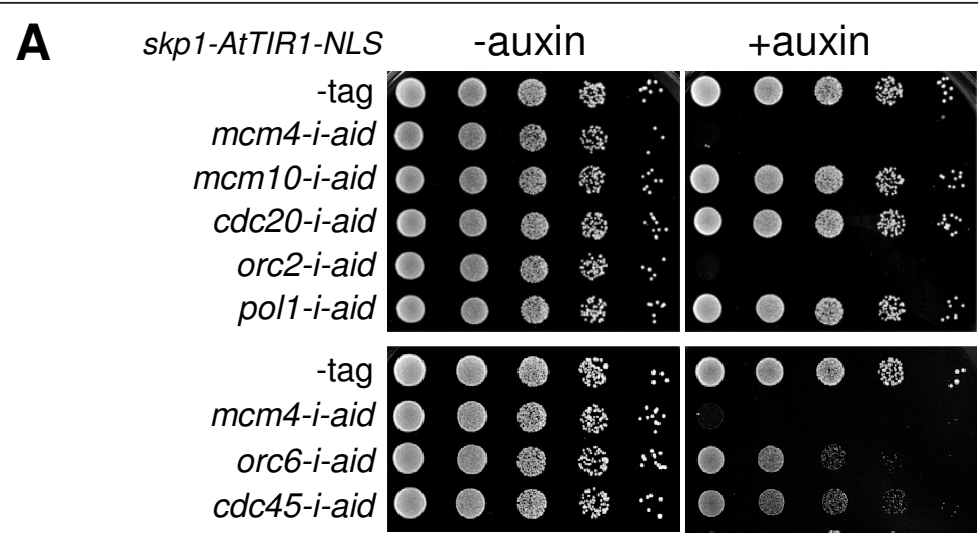

B
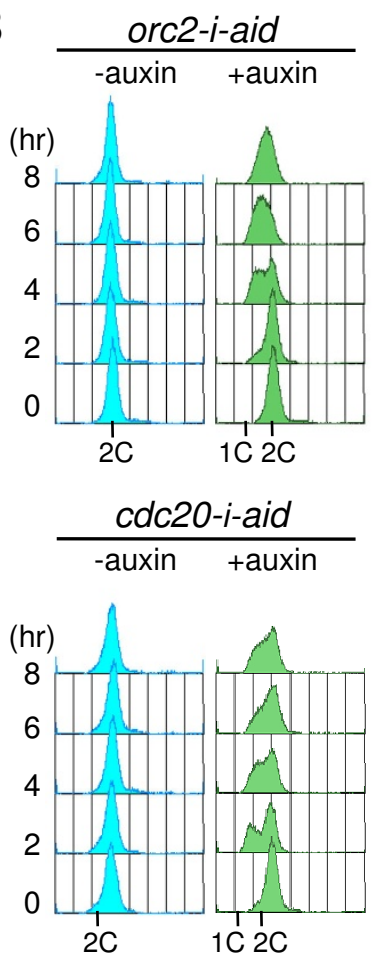
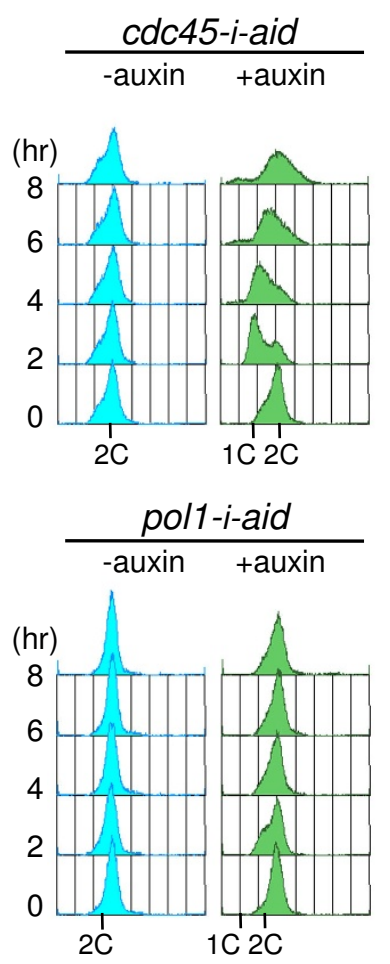

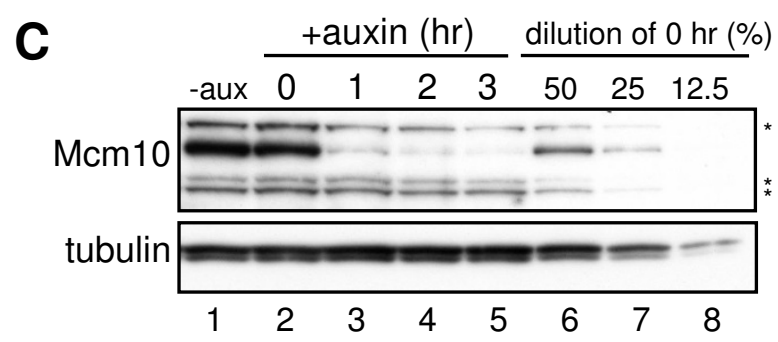

Figure 5 Application of the i-AID system to other replication factors. (A) Derivatives of the Padh15-skp1-AtTIR1-NLS strain carrying mcm4-aid (HM2473), mcm10-aid (HM2550), cdc20-aid (HM2551), orc2-aid (HM2572), pol1-aid (HM2552), orc6-aid (HM2575) and cdc45-aid (HM2578) were spotted on EMM plates containing auxin $(0.5 \mathrm{mM})$ and incubated at $25^{\circ} \mathrm{C}$. (B) Flow cytometry analysis of the derivatives shown in (A). Each strain was incubated in the presence of auxin $(0.5 \mathrm{mM})$ at $25^{\circ} \mathrm{C}$ and the DNA contents were analyzed. (C) Immunoblotting analysis of Mcm10-aid.

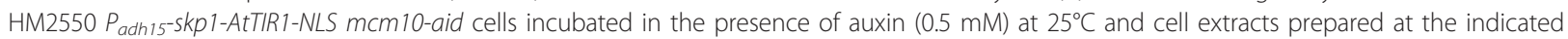
time points were subjected to immunoblotting with anti-Mcm10 and anti-TAT1 antibodies. The $0 \mathrm{~h}$ sample was diluted to 50\%, 25\% and 12.5\% with SDS sample buffer, and used for comparison of the protein amounts. Non-specific protein bands are indicated by asterisks $\left(^{*}\right)$. 
Table 1 Auxin-induced growth defects in aid-tagged strains

\begin{tabular}{|c|c|c|c|c|}
\hline Gene & Protein function & AID & i-AID & off-AID \\
\hline mcm4 & MCM subunit & $+^{*}$ & $++^{*}$ & NT \\
\hline orc2 & ORC subunit & NT & $++^{*}$ & NT \\
\hline orc4 & ORC subunit & NT & $++^{*}$ & $++^{*}$ \\
\hline orc6 & ORC subunit & NT & $+^{*}$ & NT \\
\hline psf1 & GINS subunit & NT & $t^{*}$ & $++^{*}$ \\
\hline pol1 & catalytic subunit of Pola & NT & $-*$ & $++^{*}$ \\
\hline pol12 & second largest subunit of Pola & NT & $+^{*}$ & $++^{*}$ \\
\hline spp2 & primase subunit of Pol $\alpha$ & NT & $+^{*}$ & $++^{*}$ \\
\hline $\operatorname{cdc} 20$ & catalytic subunit of Pole & NT & $-^{*}$ & $++^{*}$ \\
\hline$d p b 2$ & second largest subunit of Pole & NT & $t^{*}$ & $++^{*}$ \\
\hline $\operatorname{cdc} 45$ & replication factor & NT & $+^{*}$ & $++^{*}$ \\
\hline mem10 & replication factor & NT & - & $++^{*}$ \\
\hline hsk1 & catalytic subunit of DDK & NT & - & ++ \\
\hline$s s / 3$ & cohesin loader & NT & - & ++ \\
\hline cial & histone chaperone & NT & - & ++ \\
\hline
\end{tabular}

++ : severe growth defect on plates containing $0.5 \mathrm{mM}$ auxin for AID and $i$ AID, or $0.5 \mathrm{mM}$ auxin with $10 \mu \mathrm{g} / \mathrm{ml}$ thiamine for off-AID, +: slow growth on plates containing $0.5 \mathrm{mM}$ auxin, -: no effect, NT: not tested, *: defect of DNA replication observed in flow cytometry analysis.

at $1 \mathrm{~h}$ after auxin addition (Figure 3), suggesting the utility of this system for depletion of the protein within a short period during the cell cycle. Although the $i$-AID system resulted in retardation of DNA replication and cell growth for more than half (11 among 15) of essential factors tested, significant defect was not observed for the mcm10-i-aid, hsk1-i-aid, ssl3-i-aid and cia1-i-aid (Figure 5 and Table 1). For the latter cases, the amount of remaining tagged protein seems to be higher (20-30\% of the native amount) than those showing the defect (Figure 5C and data not shown). Difference in degradation efficiency might be caused by the affinity of TIR1 with the target proteins or the efficiency of ubiquitination in different targets. In addition, whether or not depletion of a protein causes severe phenotype may depend on the amount of protein required for its function. However, for the proteins that were not efficiently depleted by the $i$-AID system, the off-AID system that combines transcription repression with the $i$-AID system would be advantageous. The off-AID system promoted a reduction of the Cdc45-aid and Pol1-aid proteins to almost undetectable levels, causing severe defects in DNA replication. In addition, essential proteins unrelated to replication such as Ssl3 that is involved in sister chromatid cohesion and Cia1/Asf1 required for histone deposition can be depleted by the off-AID system to cause severe growth defects (Table 1). Therefore, this approach appears to be widely applicable for in vivo protein depletion in fission yeast.

In comparison of the AID system with previously published strategies, the AID system has several advantages.
Comparing the flow cytometry results by depletion of the same target protein Mcm4, mcm4-i-aid cells remained with a sharp 1C DNA peak as long as $8 \mathrm{hr}$, whereas DNA content significantly increased after $3 \mathrm{hr}$ incubation in $m c m 4 t s-t d$ cells (Figure 3F and [10]), suggesting that the $i$-AID system achieved tight cell cycle arrest in early $\mathrm{S}$ phase. In contrast to ts-degron, which requires hightemperature shift or sometimes temperature-sensitive allele of the target gene, the AID system promotes the degradation by addition of a synthetic auxin to the culture. This allows use of the $c d c 25-22$ temperaturesensitive mutation for cell cycle synchronization. Furthermore, the off-AID system causes more extensive depletion than the $i$-AID system alone (Figure 6 and data not shown). On the other hand, there are some disadvantages of the off-AID system. It requires two-step modifications of target genes; fusion of the aid-tag sequence at the $\mathrm{C}$-terminus and replacement of the promoter with the $n m t 81$ promoter. The N-terminally aid-tagged pol1Noff-aid, cdc20-Noff-aid and mcm10-Noff-aid strains, which were constructed by one-step replacement of the $\mathrm{N}$-terminus of the gene, did not exhibit significant defect in cell growth or DNA replication (data not shown). A limitation of the AID system we noticed is that the degradation efficiency decreases at high temperature $\left(36^{\circ} \mathrm{C}\right)$. Although use of OsTIR1 instead of AtTIR1 have overcome this problem in budding yeast and DT40 AID systems [11], mcm4-i-aid strain expressing $P_{\text {adh } 15^{-}-\mathrm{k} p 1 \text { - }}$ OsTIR1 in fission yeast did not improve degradation efficiency at $36^{\circ} \mathrm{C}$ (data not shown).

A remarkable feature of the $i$-AID system was that it selectively degraded Mcm4-aid protein from the MCM complex without depleting the other subunits (Figure 4). This feature would make the system suitable for functional analysis of single components of a large complex. This property is attributable to the ubiquitin-mediated protein degradation system, as reported for the $t s$-degron system in budding yeast [5]. It was also notable that the $i$-AID system degraded Mcm4-aid protein not only in the soluble fraction but also in the chromatin-bound MCM complex (Figure 4). In HU-arrested cells, where the replication machinery stalls near the replication origin, depletion of Mcm4-aid protein caused dissociation of Mcm6 from chromatin, probably along with the other subunits. Consistently, replication did not resume after removal of $\mathrm{HU}$, because the MCM complex is required as a replicative helicase for fork progression (Figure 4). Therefore, depletion of a component of the chromatin-bound complex, such as the replication fork, would be a powerful tool for analyzing the functions of chromatin proteins at specific stages of the reaction. It is likely that cytosolic proteins in fission yeast are also susceptible to auxindependent degradation, as has been described [11], although we did not test them in the present study. 


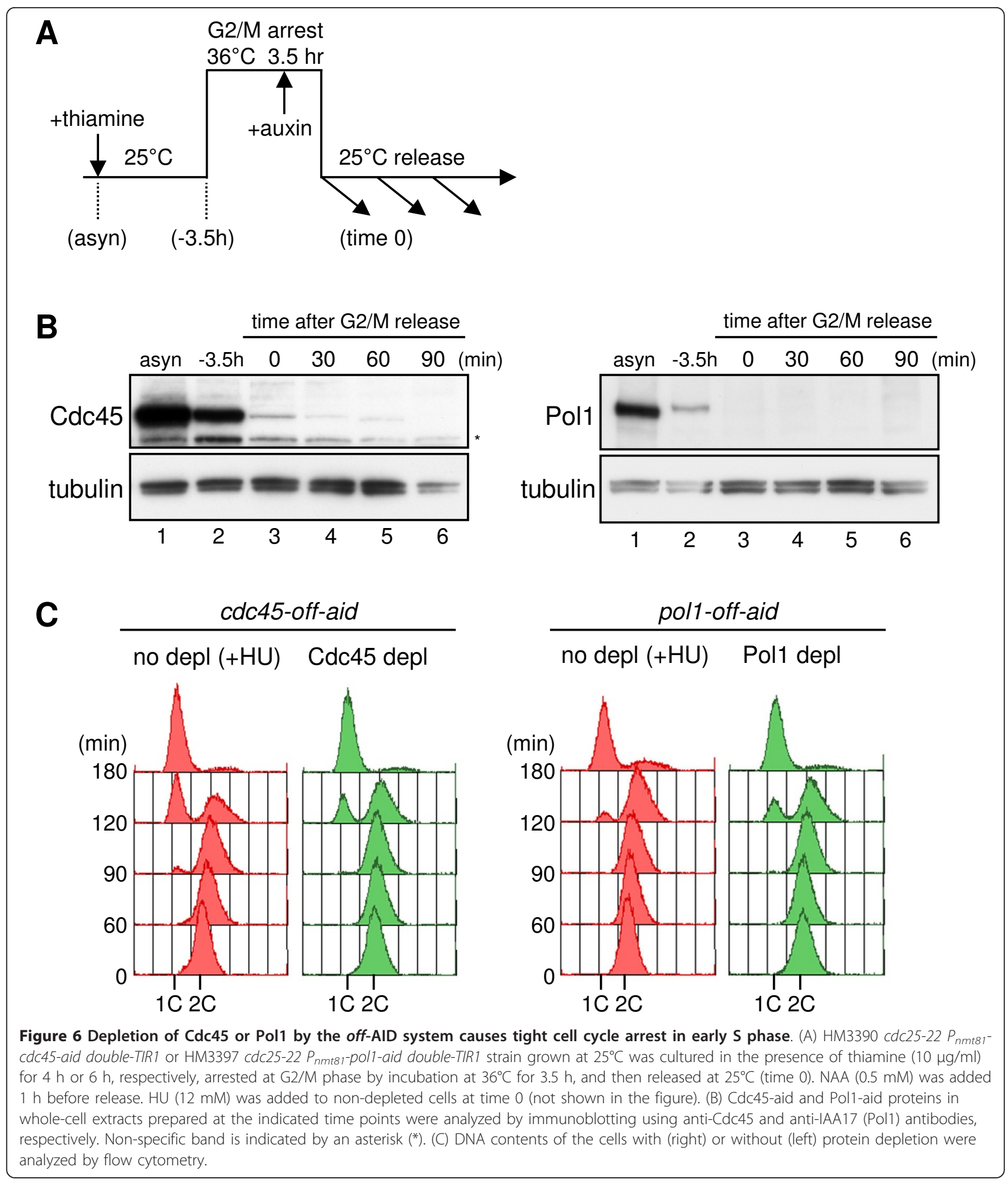

The mcm4-i-aid strain exhibited the most marked defects in growth and replication upon addition of auxin among the aid-tagged strains tested (Table 1). This is probably because a significantly large number of MCM complexes need to be loaded onto several hundred replication origins on the chromosomes [35] within the short G1 phase in the fission yeast cell cycle. Once the MCM complexes on chromatin have dissociated through degradation of Mcm4-aid protein in S phase, cells are unable to resume DNA replication because 
loading of the MCM complex onto chromatin is strongly inhibited after onset of S phase in order to avoid re-replication [36].

\section{Conclusion}

We provided an improved auxin-indusible degron system for fission yeast. The $i$-AID system, where TIR1 is fused with fission yeast Skp1, greatly enhanced degradation efficiency of Mcm4-aid protein, and the off-AID system, which combines the $i$-AID system with transcription repression, successfully depleted Cdc45-aid and Pol1-aid proteins causing arrest at early $\mathrm{S}$ phase. The off-AID system is a powerful method for depletion of specific proteins within fission yeast cells.

\section{Methods}

\section{Strains and media}

Schizosaccharomyces pombe strains used in this study are listed in Table 2. Constructions of strains HM1813, HM1905, HM2473, HM2475, HM2491, HM2550, HM2551, HM2552, HM2572, HM2575, HM2578, HM3150 and HM3325 are described in detail below. Media used for fission yeast cultivation were YE medium as a complete medium and EMM medium as a selection medium [37]. All solid media contained $2.0 \%$ agar. Transcription from the $n m t$ promoter was induced in the absence of thiamine. Transformation of S. pombe was performed by the lithium acetate method [38] and hygromycin B (Wako) and ClonNAT (WERNER BioAgents) were used for selection of transformants at final concentrations of $150 \mu \mathrm{g} / \mathrm{ml}$ and $100 \mu \mathrm{g} / \mathrm{ml}$, respectively. EMM medium was used for selection with clonNAT, while PMG medium was used for hygromycin B because of higher sensitivity to hygromycin B on PMG plates than EMM plates. A synthetic auxin, NAA (1-naphthaleneacetic acid), (Nacalai Tesque), which is commercially available at a low cost (one dollar per gram), was added at a concentration of $0.5 \mathrm{mM}$ to YE or EMM medium.

\section{Construction of $\mathrm{P}_{\mathrm{nm}+41}$-AtTIR1 strain}

To introduce AtTIR1 gene under control of $\mathrm{P}_{\mathrm{nmt} 41}$, AtTIR1-9myc sequence was introduced between the nmt41 promoter and terminator sequences [39] on pUCnmt41 to generate pKM15. Then a $4.4 \mathrm{~kb}$ Not I fragment from pKM15 containing $P_{n m t 41}$-AtTIR1-9myc- $T_{n m t 1}$ from pKM15 was inserted into the NotI site downstream of ade $^{+}$in pKM17 to generate pKM21. pKM21 was digested by EcoRI and used for transformation of TNF47 ( $h$ ade6X ura4-D18) to gain HM1813 ( $h^{-} P_{n m t 41}$-AtTIR1-9myc ura4D18). Integration of the fragment was confirmed by PCR.

\section{Construction of mcm4-aid strains}

To fuse the aid-tag (IAA17) at the C-terminal of $\mathrm{mcm}^{+}$, fragments containing the C-terminal region of $\mathrm{mcm}^{+}$
Table 2 Fission yeast strains used in this study

\begin{tabular}{|c|c|c|}
\hline $\begin{array}{l}\text { Strain } \\
\text { name }\end{array}$ & Genotype & Source \\
\hline 972 & $h^{-}$ & Lab stock \\
\hline TNF47 & hi ade6X ura4-D18 & Lab stock \\
\hline HM1813 & he ade6::ade6 ${ }^{+}-P_{n m t 41}-$ AtTIR1-9myc ura4-D18 & This work \\
\hline HM1905 & $\begin{array}{l}h \text { ade6::ade6 }{ }^{+}-P_{n m t 41}-\text { AtTIR1-9myc mcm4::mcm4- } \\
\text { 2HA-IAA17 }\end{array}$ & This work \\
\hline HM1909 & h' mcm4::mcm4-2HA-IAA17 & This work \\
\hline HM1910 & $h^{+}$mcm4::mcm4-2HA-IAA17 leu1-32 & This work \\
\hline HM2423 & $h^{-}$mcm4::mcm4-2HA-IAA17 ade6X & This work \\
\hline HM2468 & 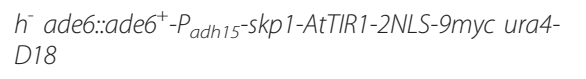 & This work \\
\hline HM2473 & $\begin{array}{l}h^{-} \text {ade6::ade6 }{ }^{+}-P_{\text {adh } 15^{-} \text {-Skp 1-AtTIR1-2NLS-9myc }} \\
\text { mcm4::Imcm4-2HA-IAA17 }\end{array}$ & This work \\
\hline HM2475 & $\begin{array}{l}\text { he ade6::ade6 }+P_{\text {adhs1-skp 1-AtTIR1-2NLS-9myc }} \\
\text { mcm4::mcm4-2HA-IAA17 }\end{array}$ & This work \\
\hline HM2491 & $\begin{array}{l}h^{-} \text {ade6::ade6 }+P_{n m t 41}-\text { skp 1-AtTIR1-2NLS-9myc } \\
\text { mcm4::mcm4-2HA-IAA17 }\end{array}$ & This work \\
\hline HM2550 & $\begin{array}{l}h^{-} \text {ade6::ade6 }{ }^{+}-P_{\text {adh } 15} \text {-skp1-AtTIR1-2NLS-9myc } \\
\text { mem10::mcm10-IAA17 }\end{array}$ & This work \\
\hline HM2551 & 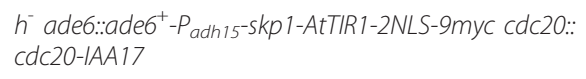 & This work \\
\hline HM2552 & 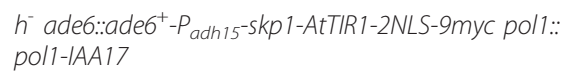 & This work \\
\hline HM2572 & $\begin{array}{l}h^{-} \text {ade6::ade6 }{ }^{+}-P_{\text {adh } 15} \text {-skp1-AtTIR1-2NLS-9myc orc2:: } \\
\text { orc2-IAA17 }\end{array}$ & This work \\
\hline HM2575 & 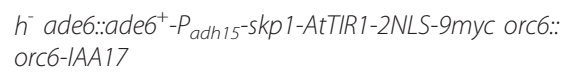 & This work \\
\hline HM2578 & $\begin{array}{l}\text { h ade6::ade6 }{ }^{-}-P_{\text {adh15-skp 1-AtTIR1-2NLS-9myc cdc45:: }} \\
\text { cdc45-IAA17 }\end{array}$ & This work \\
\hline HM2580 & $h^{-} \operatorname{cdc} 45: \cdot c d c 45-1 A A 17$ & This work \\
\hline HM2985 & 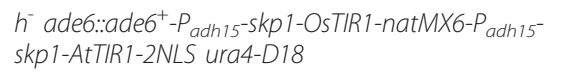 & This work \\
\hline HM3086 & $\begin{array}{l}h^{-} \text {cdc25-22 ade6:: ade6 }{ }^{+}-P_{\text {adh } 15^{-} \text {-skp1-AtTIR1-2NLS- }} \\
\text { 9myc mcm4::mcm4-2HA-IAA17 }\end{array}$ & This work \\
\hline HM3150 & 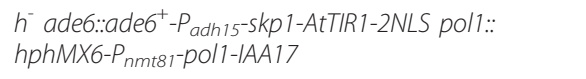 & This work \\
\hline HM3325 & $h^{-}$cdc45::hphMX6-P ${ }_{n m+81-c d c 45-I A A 17}$ & This work \\
\hline HM3390 & 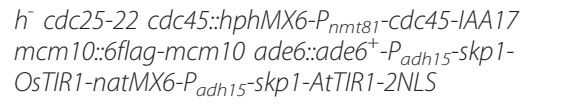 & This work \\
\hline HM3397 & 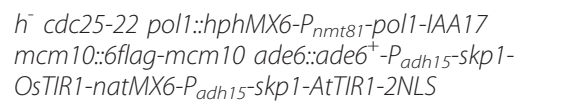 & This work \\
\hline MKF53 & $h^{+}$mcm4::mcm4-2HA-IAA17 leu1-32 pREP41D & This work \\
\hline MKF54 & $\begin{array}{l}h^{+} \text {mcm4:.:mcm4-2HA-IAA17 leu1-32 pREP41D- } \\
\text { AtTIR1-9myc }\end{array}$ & This work \\
\hline MKF55 & $\begin{array}{l}h^{+} \text {mcm4::mcm4-2HA-IAA17 leu1-32 pREP41D- } \\
\text { AtTIR1-2NLS-9myc }\end{array}$ & This work \\
\hline MKF60 & $\begin{array}{l}h^{+} \text {mcm4::mcm4-2HA-IAA17 leu1-32 pREP41D-skp1- } \\
\text { AtTIR1-9myc }\end{array}$ & This work \\
\hline
\end{tabular}

(814- to 911-amino acid) and the 3'-UTR (7 to $340 \mathrm{bp}$ downstream of the open reading frame) were amplified by PCR using the primers mcm $4 \mathrm{C}-\mathrm{F}$ and $\mathrm{mcm} 4 \mathrm{C}-\mathrm{R}$, and mcm $4 \mathrm{dw}-\mathrm{F}$ and $\mathrm{mcm} 4 \mathrm{dw}-\mathrm{R} 2$ (Table 3), respectively. The C-terminal fragment was cloned into the NdeI-SmaI site of 
Table 3 Primers used in this study

\begin{tabular}{|c|c|}
\hline Primer name & Sequence \\
\hline IAA17-2HA-R & 5'-AAAATGCATTGCTGCAGCTCGAGCTCTGCTCTTGCAC-3' \\
\hline IAA17-2HA-F & $\begin{array}{l}\text { 5'-AAAATGCATGCTGCAGCTCGAGCATACCCATACGATGTACCTGATTATGC } \\
\text { TGGTTATCCTTATGATGTTCCAGACTATGCTATGATGGGCAGTGTCGAG-3' }\end{array}$ \\
\hline $\mathrm{mcm} 4 \mathrm{C}-\mathrm{F}$ & 5'-GGAATTCCATATGACTAGTGCAACTGATCCTGCAACAGGA-3' \\
\hline $\mathrm{mcm} 4 \mathrm{C}-\mathrm{R}$ & 5'-TTCCCCCGGGTTATCGTCGACTACCTGCAGGATCAGTATGTGCAATTGAACGTAC-3' \\
\hline $\mathrm{mem} 4 \mathrm{dw}-\mathrm{F}$ & 5'-GGGGTACCGAATTCAGCGAATAAGCTGGTATTATTCATGAGC-3' \\
\hline $\mathrm{mem} 4 \mathrm{dw}-\mathrm{R} 2$ & 5'-GGAAGATCTGGATCCTCGAGCTACGAATCATGGCGAATTATTGGTTACG-3' \\
\hline skp1-F & 5'-CCATCGATCATATGGCTAGCCCTGCAGGGATGTCCAAAATCAAACTGATTTCATCTGAC-3' \\
\hline skp1-R & 5'-GGAATTCACTAGTCAGATCTCCTGCGCCGGCTCCAGCACCAAGATCTGGGATCCCTCTGTCTTCGGCCC-3' \\
\hline cdc20-IAA & 5'-TCGACACTGCCCATCATAGCTGCGGAAGTTGAGTTCAGCACAGAAAGTA-3' \\
\hline cdc20-ura & 5'-GTTTCGTCAATATCACAAGCCTCGCCTGACCATGAGC-3' \\
\hline$c d c 20-d w-R$ & 5'-CGAACGTTTAAGAGCATG-3' \\
\hline cdc20C-F & 5'-GACATGGGGACCTTGGTG-3' \\
\hline mcm10-IAA & 5'-TCGACACTGCCCATCATAGCAGCGGAAGTTGAGGGAACTATTTCTAAGTC-3' \\
\hline mcm10-ura & 5'-GTTTCGTCAATATCACAAGCGACTTAGAAATAGTTCCC-3' \\
\hline$m c m 10-d w-R$ & 5'-GCTTACAAGCCCATCATACC-3' \\
\hline mcm10C-F & 5'-CCCTAAATCCTCTCTACC-3' \\
\hline cdc45-IAA & 5'-TCGACACTGCCCATCATCGTTCCTTGTGGTAGTGTTTTGAAGGACAGAC-3' \\
\hline cdc45-ura & 5'-GTTTCGTCAATATCACAAGCTCCACACCAGCAATTGTT-3' \\
\hline$c d c 45-d w-R$ & 5'-TGACTGATCCAGAATCGG-3' \\
\hline $\mathrm{cdc} 45 \mathrm{C}-\mathrm{F}$ & 5'-GCATCCCCTTGCGTTAAC-3' \\
\hline orc2-IAA & 5'-TCGACACTGCCCATCATCGTTCCTTGTGGTACGTCTTCCATCATATCC-3' \\
\hline orc2-ura & 5'-GTTTCGTCAATATCACAAGCGGACCCTITTAGACTAGG-3' \\
\hline orc $2-d w-R$ & 5'-TACAATGCTGATACTAGGA-3' \\
\hline $\operatorname{orc} 2 \mathrm{C}-\mathrm{F}$ & 5'-TCTCTATTCTTTGCCCGCC-3' \\
\hline orc6-IAA & 5'-TCGACACTGCCCATCATCGTTCCTTGTGGTGAAGCAGTACCATCTIITTC-3' \\
\hline orc6-ura & 5'-GTTTCGTCAATATCACAAGCCGGGTACACGATATCTTTAG-3' \\
\hline orc6-dw-R & 5'-CAATGATTCTCAAGAGACG-3' \\
\hline orc6C-F & 5'-ACTAGTATCGGCAAAAGCTTTTG-3' \\
\hline pol1-IAA & 5'-TCGACACTGCCCATCATCGTTCCTTGTGGCGATGAAAATATCAGTCCC-3' \\
\hline pol1-ura & 5'-GTTTCGTCAATATCACAAGCCTACCCGTTTAAGTAATCTAC-3' \\
\hline pol1-dw-R & 5'-GTCAAACATGTAGTGAGTAC-3' \\
\hline pol1C-F & 5'-CTCATCTCAACTCAGAGA-3' \\
\hline TIR1C-BmSc & 5'-CGGGATCCGCGGAGACAGTGACTTAGGCAT-3' \\
\hline TIR1-NLS-R & 5'-CGGGATCCTTAGTCGACCACTTTGCGTTITTCTITGG-3' \\
\hline pol1N-nmt-F & 5'-CTTATAGTCGCTTTGTTAAATCATATGAGAAAGAGAAACGCGGG-3' \\
\hline pol1up-F-Spe & 5'-GGACTAGTCGTGCTTCAAGTATTTCCCG-3' \\
\hline pol1up-R-Bgl & 5'-GAAGATCTGTTCACGAGAAGACTTTAAAG-3' \\
\hline pol1dw-R-Bm & 5'-CGGGATCCCGACCAGACGATCCTTTTTC-3' \\
\hline cdc45up-F-Spe & 5'-GGACTAGTCGTTGTGCACATGTTCACCT-3' \\
\hline cdc45up-R-Bm & 5'-CGGGATCCACGTTACTGGTGGTGGATCA-3' \\
\hline ars2004 region-273F & 5'-CGGATCCGTAATCCCACAAA-3' \\
\hline ars2004 region-338R & 5'-TTGCTTACATTTTCGGGAACTTA-3' \\
\hline nonARS1 region-514F & 5'-TACGCGACGAACCTTGCATAT-3' \\
\hline nonARS1 region-583R & 5'-TTATCAGACCATGGAGCCCAT-3' \\
\hline
\end{tabular}

pUC-nmt1, resulting in pKM37. The 3'-UTR fragment was introduced into the KpnI-BamHI site of the plasmid containing the $\mathrm{ura}^{+}$gene to generate pKM38. The Nterminally $2 \mathrm{HA}$-tagged IAA17 fragment (2HA-aid) was amplified by PCR using the primers IAA17-2HA-F and
IAA17-2HA-R (Table 3) and pRS304 as a template, and then introduced at the C-terminus of $m c m 4$ on pKM37 to generate $\mathrm{pKM} 39$. The $m c m 4 C$ - $2 \mathrm{HA}$-aid fragment from pKM39 was cloned into pKM38 to create pKM40, containing $m c m 4 C-2 H A$-aid-ura $4^{+}-m c m 4 D W$. SalI-XhoI-digested 
pKM40 was used for transformation of HM1813 $\left(h^{-}\right.$

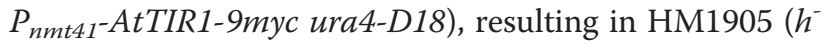
$P_{\text {nt } 41}$-AtTIR1-9myc mcm4-2HA-aid). Integration of mcm4-2HA-aid-ura4 $4^{+}$at the $m c m 4^{+}$locus was confirmed by PCR.

\section{Construction of plasmids carrying modified TIR1}

The AtTIR1-9myc and AtTIR1-NLS-9myc genes were inserted between the $n m t 41$ promoter and terminator sequences [39] on pREP41-Dual to generate pKM7 and pKM45, respectively.

To fuse fission yeast Skp1 at the N-terminus of AtTIR1, the $s k p 1$ gene lacking introns was PCR-amplified from a cDNA library (donated by H. Nojima) with a 16-amino-acid linker (Gly-Ile-Pro-Asp-Leu-Gly-AlaGly-Ala-Gly-Ala-Gly-Asp-Leu-Thr-Ser) at the C-terminal of the protein using the primers skp1-F and skp1-R (Table 3), then cloned into the ClaI-EcoRI site of pBluescriptII SK(+), resulting in pKM44. The skp1 fragment from pKM44 together with the AtTIR1-9myc fragment was inserted between the $n m t 41$ promoter and terminator sequence on pREP41-Dual to create pKM71.

pREP41-Dual, pKM7, pKM45, and pKM71 plasmids were introduced into HM1910 $\left(h^{+}\right.$mcm4-2HA-aid leu132) by electroporation to gain MKF53, MKF54, MKF55 and MKF60, respectively [40].

\section{Construction of TIR1 integrant strains}

For integration of the skp1-AtTIR1-NLS-9myc gene under control of the $n m t 41$ promoter into the $a_{d e} 6^{+}$locus, the skp1 fragment together with an AtTIR1-NLS-9myc fragment was inserted between the $n m t 41$ promoter and terminator sequences on pUC-nmt41, resulting in pKM82. Then NotI fragment containing $P_{n m t 41}$-skp1-AtTIR1-NLS$9 m y c-T_{n m t 1}$ from pKM82 was inserted into the NotI site downstream of ade $^{+}$in pKM17 to generate pKM84.

For construction of the skp1-AtTIR1-NLS gene under control of weak derivatives of the $a d h 1$ promoter, the nmt41 promoter of pKM84 was replaced by promoter fragments from pRAD15 and pRAD81 (provided by Y. Watanabe), resulting in pKM104 and pKM105, respectively. Then pKM84, pKM104 and pKM105 were digested by EcoRI and used for transformation of HM2423 ( $h^{-}$mcm4$2 H A$-aid ade6X) to generate HM2491 ( $h^{-}$mcm4-2HA-aid

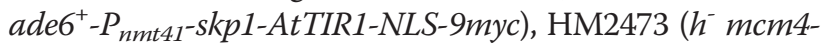
2HA-aid ade6 ${ }^{+}-P_{\text {adh15-skp1-AtTIR1-NLS-9myc) and }}$ HM2475 ( $h$ mcm4-2HA-aid ade6 ${ }^{+}-P_{\text {adh81-skp1-AtTIR1- }}$ $N L S-9 m y c)$, respectively. Integration of skp1-AtTIR1-NLS$9 m y c$ at the ade $^{+}$locus was confirmed by genomic PCR.

\section{Construction of aid-tagged derivatives of replication factors}

The $\mathrm{mcm} \mathrm{O}^{+}$gene was $\mathrm{C}$-terminally tagged with IAA17 peptide using PCR. The integration cassette was amplified by two-step PCR amplification. The first PCR amplified fragments from the $972\left(h^{-}\right.$, wild type) genome containing the C-terminal region of $\mathrm{mcm} 1 \mathrm{O}^{+}$linked with part of the aid-tag, and the 3'-UTR of $m c m 10^{+}$linked with part of the selection marker $\left(\mathrm{ura}^{+}\right)$gene, using the primer sets mcm10C-F and mcm10-IAA, and mcm10-ura and mcm10-dw-R (Table 3), respectively. The second PCR amplified the integration cassette from pKM40 with the primers mcm10C-F and mcm10-dw-R, and the two short fragments made by the first PCR reactions. The products of the second PCR were then used for transformation of HM2468 $\left(h^{-} P_{\text {adh15-skp }}\right.$ AtTIR1-NLS-9myc ura4-D18). Transformants were selected on an EMM plate, and the integration of the aid-tag was confirmed by genomic sequencing. The resulting strain, HM2550 ( $h^{-} P_{\text {adh15-skp1-AtTIR1-NLS- }}$ $9 m y c$ mcm10-aid), showed wild-type growth, suggesting that the aid-tagged Mcm10 was functional.

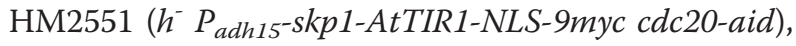

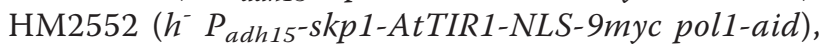

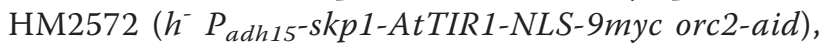

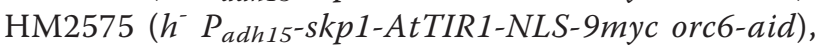

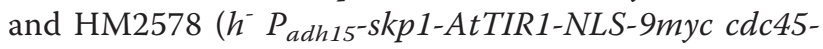
aid) were constructed similarly using pKM40 and the following primers (Table 3). HM2551: cdc20C-F and cdc20-IAA; cdc20-ura and cdc20-dw-R, HM2552: pol1C-F and pol1-IAA; pol1-ura and pol1-dw-R, HM2572: orc2C-F and orc2-IAA; orc2-ura and orc2-dwR, HM2575: orc6C-F and orc6-IAA; orc6-ura and orc6dw-R, and HM2578: cdc45C-F and cdc45-IAA; cdc45ura and cdc45-dw-R. All the strains showed wild-type growth, except for HM2578, which grew slightly more slowly in the absence of auxin.

\section{Construction of the double-TIR1 strain}

For integration of the skp1-OsTIR1-NLS-9myc gene under control of the adh15 promoter into the ade $6^{+}$ locus, a $1.7-\mathrm{kb} X b a \mathrm{I}-S a l \mathrm{I}$ fragment containing the OsTIR1 gene from pNHK33 and a 0.4 kb SalI-SmaI fragment containing $9 m y c$ were introduced into the SpeISmaI sites of pKM104 to generate pKM111. pKM111 was digested by EcoRI and used for transformation.

To remove the 9myc-tag at the C-terminus of AtTIR1, the C-terminal region of AtTIR1-NLS without myc-tag was PCR-amplified using the primers TIR1C-BmSc and TIR1-NLS-R (Table 3), and the products obtained by BamHI digestion were used to generate pKM132, which contains the C-terminal region of AtTIR1-NLS and the transcription terminator $T_{n m t}$. The C-terminal region of skp1-AtTIR1-NLS-9myc was replaced by the NsiI-SmaI fragment from pKM132, to generate pKM136 carrying $P_{\text {adh15-skp1-AtTIR1-NLS- } T_{\text {nmt1 }} \text {. }}$.

To construct the double-TIR1 strain, the SpeI-NotI fragment from pKM132 containing the C-terminal region of 
AtTIR1-NLS and $T_{n m t 1}$ was inserted into pKM126 containing the 3'-UTR of $a d e 6^{+}$, resulting in pKM135. Then the XhoI-SalI fragment containing the OsTIR1 gene was introduced into the SalI site of pKM135 to create pKM143, carrying OsTIR1-T $T_{n m t 1}$ and the 3'-UTR of ade ${ }^{+}$. Then the selection marker gene, natMX6, cloned from pFA6a-natMX6 and the $P_{\text {adh15-skp1-AtTIR1-NLS-T }}$ nmt1 gene from pKM136 were inserted into the NotI site of pKM143 to generate pKM151. An $8.2 \mathrm{~kb}$ SacII fragment from pKM151 containing OsTIR1- $T_{n m t 1}$, natMX6, $P_{\text {adh15- }}$ skp1-AtTIR1-NLS-T $T_{n m t 1}$ and the 3'-UTR of ade6 ${ }^{+}$was introduced into cells harboring $P_{\text {adh15-skp1-OsTIR-9myc at }}$ the ade $^{+}$locus to construct the double-TIR1 strain. A $\mathrm{Nat}^{\mathrm{R}}$ transformant that grew on an EMM plate containing clonNAT $(100 \mu \mathrm{g} / \mathrm{ml})$ was obtained, and integration of the fragment was confirmed by genomic PCR and southern hybridization.

\section{Construction of $P_{n m t 81}$-pol1-aid and $P_{n m t 81}$ - cdc45-aid strains}

For construction of the $P_{n m t 81-p o l 1-a i d}$ strain, the 5'-UTR of pol1 $^{+}$was amplified by PCR using the primers pol1upF-Spe and pollup-R-Bgl (Table 3), and the SpeI-BglIIdigested product was cloned into the SpeI-BamHI sites upstream of hphMX6 to generate pKM154. The N-terminal region of pol1 $1^{+}$was PCR-amplified using the primers pol1N-nmt-F and pol1dw-R-Bm (Table 3), and the product was digested by $N d e \mathrm{I}$ and $B a m \mathrm{HI}$, and then cloned into the NdeI-BamHI sites downstream of $P_{n m t 81}$ to create pKM158. Then $S a c$ I fragment of pKM154 containing the 3'-UTR of pol1 $1^{+}$and $h p h M X 6$ was introduced into the SacI site of pKM158 to form pKM159. pKM159 was digested by EcoRV and used for transformation of

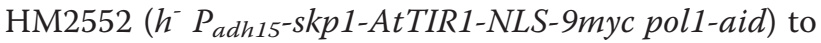

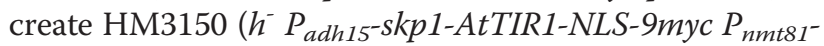
pol1-aid). The insertion was confirmed by genomic PCR.

A strain expressing Cdc45-aid from $P_{n m t 81}$ was constructed as described below. The $\mathrm{N}$-terminal fragment of $c d c 45^{+}$was cloned from pGAD-Cdc45 into the NdeIEcoRV sites of pKM158 to create pKM163. The 5'-UTR of $c d c 45^{+}$was PCR-amplified using the primers cdc45up-F-Spe and cdc45up-R-Bm (Table 3), and the product digested by $S p e \mathrm{I}$ and $\mathrm{BamHI}$ was cloned into the SpeI-BamHI sites upstream of $h p h M X 6$, resulting in pKM164. The 2.0-kb SacI fragment containing the 3'UTR of $c d c 45^{+}$and $h p h M X 6$ was inserted into the SacI site of pKM163 to create pKM165. pKM165 was used for transformation of HM2580 ( $h^{-} c d c 45$-aid) to generate HM3325 $\left(h^{-} P_{n m t 81}-c d c 45\right.$-aid $)$, and the integration was confirmed by genomic PCR.

\section{Preparation of cell extracts and immunoblotting}

S. pombe cells $\left(1 \times 10^{8}\right.$ cells $)$ were fixed with $20 \%$ TCA and suspended in $0.1 \mathrm{ml}$ of urea solution $(50 \mathrm{mM} \mathrm{NaPi}$
[pH 8.0], $8 \mathrm{M}$ urea, $1 \mathrm{mM}$ DTT, 0.1\% Nonidet P-40). Cells were disrupted with acid-washed glass beads using a Micro Smash (TOMY) three times for $45 \mathrm{sec}$ each time. Proteins in the extracts were separated by SDSPAGE and transferred onto PVDF membrane (Immobilon, Millipore Corp). The membranes were incubated for $1 \mathrm{~h}$ at room temperature in PBST $(10 \mathrm{mM}$ $\mathrm{Na}_{2} \mathrm{HPO}_{4}, 137 \mathrm{mM} \mathrm{NaCl}, 2.7 \mathrm{mM} \mathrm{KCl}, 1.76 \mathrm{mM}$ $\mathrm{KH}_{2} \mathrm{PO}_{4}, 0.1 \%$ Tween 20) containing 5\% skim milk and reacted in PBST containing 1\% skim milk overnight at $4^{\circ} \mathrm{C}$ with rabbit anti-Mcm4 antibody [41], rabbit antiMcm2 antibody [33], rabbit anti-Mcm3 antibody [42], rabbit anti-Mcm5 antibody [33], rabbit anti-Mcm6 antibody [33], rabbit anti-Mcm7 antibody [42], rabbit antiMcm10 antibody (will be published elsewhere), rabbit anti-Cdc45 antibody [43], rabbit anti-IAA17 antibody [11], mouse anti-Myc antibody 9E11 (NeoMarkers) or mouse anti-TAT1 antibody [44] at dilutions of 1:2,000, $1: 1,000,1: 3,000,1: 1,000,1: 3,000,1: 1,000,1: 2,000$, $1: 2,000,1: 2,000,1: 1,000$ and $1: 500$, respectively. HRPconjugated anti-mouse or anti-rabbit immunogloblin G was used as the secondary antibody (1:10,000; Jackson). Binding was visualized with West Pico Chemiluminescent Substrate and Femto Maximum Sensitivity Substrate (Thermo).

\section{Cell cycle synchronization}

To synchronize the cell cycle, the thermosensitive mutation $c d c 25-22$ was used for G2/M arrest [26]. Derivatives carrying $c d c 25-22$ were incubated at $36^{\circ} \mathrm{C}$ for $3 \mathrm{~h}$ for arrest at the $\mathrm{G} 2 / \mathrm{M}$ boundary and then released at $25^{\circ} \mathrm{C}$. To repress transcription, thiamine was added at a final concentration of $10 \mu \mathrm{g} / \mathrm{ml}$ at the indicated time points before G2/M arrest (see Figure legends). Synthetic auxin, NAA (1-naphthaleneacetic acid) (Nacalai Tesque), was added at a concentration of $0.5 \mathrm{mM}, 1 \mathrm{~h}$ before the release from $\mathrm{G} 2 / \mathrm{M}$ to induce protein degradation.

To arrest cells in early $\mathrm{S}$ phase, cells released from the G2/M boundary were cultured for $3 \mathrm{~h}$ in the presence of $12 \mathrm{mM}$ hydroxyurea (HU, Sigma), which depletes the cellular dNTP pools. NAA was added $1 \mathrm{~h}$ before the release from HU arrest.

\section{Chromatin immunoprecipitation assay}

ChIP assays were performed as described previously [45] with some modifications. Derivatives of $c d c 25-22$ grown in EMM medium at $25^{\circ} \mathrm{C}$ for $15 \mathrm{~h}$ to $0.6 \times 10^{7}$ cells $/ \mathrm{ml}$ were arrested at the $\mathrm{G} 2 / \mathrm{M}$ boundary by incubation at $36^{\circ} \mathrm{C}$ for $3 \mathrm{~h}$ and then released at $25^{\circ} \mathrm{C}$ in the presence of $12 \mathrm{mM} \mathrm{HU}$ to retard replication forks. The cells $(3 \times$ $10^{8}$ ) were fixed in $1 \%$ formaldehyde (Sigma) for $15 \mathrm{~min}$ and then in $125 \mathrm{mM}$ glycine for $5 \mathrm{~min}$ at room temperature with gentle shaking. After being washed once with cold water, the cells were suspended in $450 \mu \mathrm{l}$ of 
breaking buffer (50 mM Hepes- $\mathrm{KOH}$ [pH 7.4], $1 \mathrm{mM}$ EDTA, $140 \mathrm{mM} \mathrm{NaCl}, 0.1 \%$ sodium deoxycholate, $0.1 \%$ Triton X-100, $1 \mathrm{mM}$ phenylmethylsulfonyl fluoride, $0.1 \%$ proteinase inhibitor cocktail [Sigma]) and disrupted with glass beads using a Micro Smash (TOMY) five times for $30 \mathrm{~s}$ each time. The cell extracts were recovered by centrifugation at 3,000 rpm for $10 \mathrm{~s}$. After addition of $50 \mu \mathrm{l}$ of $10 \%$ Triton $\mathrm{X}-100$, the samples were sonicated four times for $10 \mathrm{~s}$ each time. The supernatant obtained by centrifugation at $15,000 \mathrm{rpm}$ for $10 \mathrm{~min}$ was used for immunoprecipitation with magnet beads (Dynal) conjugated with rabbit anti-Mcm6 antibody (1:400). After incubation of the cell extracts with the beads at $4^{\circ} \mathrm{C}$ for $2 \mathrm{~h}$, the immunoprecipitates were rinsed with ChIP lysis buffer $(50 \mathrm{mM}$ Hepes- $\mathrm{KOH}[\mathrm{pH}$ 7.4], $1 \mathrm{mM}$ EDTA, $140 \mathrm{mM} \mathrm{NaCl}, 0.1 \%$ sodium deoxycholate, 1\% Triton X-100, $1 \mathrm{mM}$ phenylmethylsulfonyl fluoride) once, ChIP lysis buffer containing $640 \mathrm{mM}$ $\mathrm{NaCl}$ twice, ChIP wash buffer $(10 \mathrm{mM}$ Tris- $\mathrm{HCl}[\mathrm{pH}$ 8.0], $1 \mathrm{mM}$ EDTA, $250 \mathrm{mM} \mathrm{LiCl}, 0.5 \%$ sodium deoxycholate, $0.5 \%$ Nonidet P-40) twice and TE1 (10 mM Tris- $\mathrm{HCl}$ [pH 8.0], $1 \mathrm{mM}$ EDTA) once, and then the obtained protein-DNA complex was eluted with TES (10 mM Tris- $\mathrm{HCl}$ [pH 8.0], $1 \mathrm{mM}$ EDTA, 1\% SDS) by incubation at $65^{\circ} \mathrm{C}$ for $30 \mathrm{~min}$. To reverse the crosslinking, the eluates were incubated at $65^{\circ} \mathrm{C}$ for $15 \mathrm{~h}$. The remaining proteins were digested with Proteinase $\mathrm{K}$ (Merck) and the DNA was purified by extraction with phenol and chloroform. The DNA recovered by ethanol precipitation was suspended in TE. DNA prepared from whole-cell extracts or immunoprecipitated fractions was analyzed by real-time PCR using SYBR green I in a 7300 real-time PCR System (Applied Biosystems). The primer sets used for real-time PCR were ars2004 region-273F and ars2004 region-338R for ars2004, and nonARS1 region-514F and nonARS1 region-583R for the nonorigin region (Table 3 ).

\section{Flow cytometry}

Cells were fixed with $70 \%$ ethanol and incubated with $0.5 \mu \mathrm{g} / \mathrm{ml}$ Propidium iodide and $50 \mu \mathrm{g} / \mathrm{ml}$ RNaseA in $50 \mathrm{mM}$ sodium citrate for $1 \mathrm{~h}$ at $37^{\circ} \mathrm{C}$. Samples were then measured using a FACScan (BECTON DICKINSON).

\section{Deposit of strains}

Strains HM2468, HM2473 and HM2985 and plasmid pKM40 are deposited to the National BioResource Project http://yeast.lab.nig.ac.jp/nig/ and will be available upon request.

\section{Acknowledgements}

We thank Drs. Haruhiko Takisawa for valuable discussion and Yoshinori Watanabe and Hiroshi Nojima for kindly providing derivatives of the adh 1 promoter and S. pombe cDNA library, respectively. We also thank Mr. Tetsuya
Handa, Ryota Ueda, Makoto Yoshida, Ooi LingFan and Ms. Shuqi Yan for construction of AID strains. This study was supported by a Grant-in-Aid from the Ministry of Education, Science, Technology, Sports, and Culture, Japan, to H.M and by a Grant-in-Aid for JSPS Fellows to M.K.

\section{Author details}

${ }^{1}$ Graduate School of Science, Osaka University, 1-1 Machikaneyama-cho, Toyonaka, Osaka 560-0043, Japan. ${ }^{2}$ Current Address: National Institute of Genetics, Yata 1111, Mishima, Shizuoka 411-8540, Japan.

\section{Authors' contributions}

MKan carried out the molecular genetic studies, participated in the design of the study and drafted the manuscript. KN participated in the molecular genetic studies. MKane participated in the design of the study. TK conceived of conception of the study. TT and TN participated in the design of the study and contributed to analysis and interpretation of data. HM conceived of the study, and participated in its design and coordination. All authors read and approved the final manuscript.

Received: 9 October 2010 Accepted: 11 February 2011

Published: 11 February 2011

\section{References}

1. Gould $\mathrm{KL}$, Simanis $\mathrm{V}$ : The control of septum formation in fission yeast. Genes Dev 1997, 11(22):2939-2951.

2. Nurse P: Universal control mechanism regulating onset of $\mathrm{M}$-phase. Nature 1990, 344(6266):503-508.

3. Yanagida M: Fission yeast cut mutations revisited: control of anaphase. Trends Cell Biol 1998, 8(4):144-149.

4. Dohmen RJ, Wu P, Varshavsky A: Heat-inducible degron: a method for constructing temperature-sensitive mutants. Science 1994, 263(5151):1273-1276.

5. Labib K, Tercero JA, Diffley JF: Uninterrupted MCM2-7 function required for DNA replication fork progression. Science 2000, 288(5471):1643-1647.

6. Kanemaki M, Sanchez-Diaz A, Gambus A, Labib K: Functional proteomic identification of DNA replication proteins by induced proteolysis in vivo. Nature 2003, 423(6941):720-724.

7. Sanchez-Diaz A, Marchesi V, Murray S, Jones R, Pereira G, Edmondson R, Allen T, Labib K: Inn1 couples contraction of the actomyosin ring to membrane ingression during cytokinesis in budding yeast. Nat Cell Biol 2008, 10(4):395-406.

8. Rajagopalan S, Liling Z, Liu J, Balasubramanian M: The N-degron approach to create temperature-sensitive mutants in Schizosaccharomyces pombe. Methods 2004, 33(3):206-212.

9. Gregan J, Lindner K, Brimage L, Franklin R, Namdar M, Hart EA, Aves SJ, Kearsey SE: Fission yeast $\mathrm{Cdc} 23 / \mathrm{Mcm} 10$ functions after pre-replicative complex formation to promote Cdc45 chromatin binding. Mol Biol Cell 2003, 14(9):3876-3887.

10. Lindner K, Gregan J, Montgomery S, Kearsey SE: Essential role of MCM proteins in premeiotic DNA replication. Mol Biol Cell 2002, 13(2):435-444

11. Nishimura K, Fukagawa T, Takisawa H, Kakimoto T, Kanemaki M: An auxinbased degron system for the rapid depletion of proteins in nonplant cells. Nat Methods 2009, 6(12):917-922.

12. Chapman EJ, Estelle M: Mechanism of auxin-regulated gene expression in plants. Annu Rev Genet 2009, 43:265-285.

13. Deshaies RJ: SCF and Cullin/Ring H2-based ubiquitin ligases. Annu Rev Cell Dev Biol 1999, 15:435-467.

14. Gray WM, del Pozo JC, Walker L, Hobbie L, Risseeuw E, Banks T, Crosby WL, Yang $\mathrm{M}, \mathrm{Ma} \mathrm{H}$, Estelle M: Identification of an SCF ubiquitin-ligase complex required for auxin response in Arabidopsis thaliana. Genes Dev 1999, 13(13):1678-1691.

15. Ruegger M, Dewey E, Gray WM, Hobbie L, Turner J, Estelle M: The TIR1 protein of Arabidopsis functions in auxin response and is related to human SKP2 and yeast grr1p. Genes Dev 1998, 12(2):198-207.

16. Tan X, Calderon-Villalobos LI, Sharon M, Zheng C, Robinson CV, Estelle M, Zheng N: Mechanism of auxin perception by the TIR1 ubiquitin ligase. Nature 2007, 446(7136):640-645.

17. Kepinski S, Leyser O: The Arabidopsis F-box protein TIR1 is an auxin receptor. Nature 2005, 435(7041):446-451.

18. Dharmasiri N, Dharmasiri S, Estelle M: The F-box protein TIR1 is an auxin receptor. Nature 2005, 435(7041):441-445. 
19. Abel S, Theologis A: Early genes and auxin action. Plant Physiol 1996, 111(1):9-17.

20. Forsburg SL: Comparison of Schizosaccharomyces pombe expression systems. Nucleic Acids Res 1993, 21(12):2955-2956.

21. Basi G, Schmid E, Maundrell K: TATA box mutations in the Schizosaccharomyces pombe nmt1 promoter affect transcription efficiency but not the transcription start point or thiamine repressibility. Gene 1993, 123(1):131-136.

22. Kominami K, Ochotorena I, Toda T: Two F-box/WD-repeat proteins Pop1 and Pop2 form hetero- and homo-complexes together with cullin-1 in the fission yeast SCF (Skp1-Cullin-1-F-box) ubiquitin ligase. Genes Cells 1998, 3(11):721-735.

23. Yamagishi $Y$, Sakuno T, Shimura M, Watanabe $Y$ : Heterochromatin links to centromeric protection by recruiting shugoshin. Nature 2008, 455(7210):251-255

24. Yokobayashi S, Watanabe Y: The kinetochore protein Moa1 enables cohesion-mediated monopolar attachment at meiosis I. Cell 2005, 123(5):803-817.

25. Maraschin Fdos S, Memelink J, Offringa R: Auxin-induced, SCF(TIR1)mediated poly-ubiquitination marks AUX/IAA proteins for degradation. Plant J 2009, 59(1):100-109.

26. Russell $P$, Nurse P: cdc $25+$ functions as an inducer in the mitotic control of fission yeast. Cell 1986, 45(1):145-153.

27. Bailis JM, Luche DD, Hunter T, Forsburg SL: Minichromosome maintenance proteins interact with checkpoint and recombination proteins to promote s-phase genome stability. Mol Cell Biol 2008, 28(5):1724-1738.

28. Ishimi Y, Komamura-Kohno Y, Karasawa-Shimizu K, Yamada K: Levels of MCM4 phosphorylation and DNA synthesis in DNA replication block checkpoint control. J Struct Biol 2004, 146(1-2):234-241.

29. Ishimi Y, Komamura-Kohno Y, Kwon HJ, Yamada K, Nakanishi M: Identification of MCM4 as a target of the DNA replication block checkpoint system. J Biol Chem 2003, 278(27):24644-24650.

30. Namdar M, Kearsey SE: Analysis of Mcm2-7 chromatin binding during anaphase and in the transition to quiescence in fission yeast. Exp Cell Res 2006, 312(17):3360-3369.

31. Adachi Y, Usukura J, Yanagida M: A globular complex formation by Nda1 and the other five members of the MCM protein family in fission yeast. Genes Cells 1997, 2(7):467-479.

32. Okuno Y, Okazaki T, Masukata H: Identification of a predominant replication origin in fission yeast. Nucleic Acids Res 1997, 25(3):530-537.

33. Ogawa Y, Takahashi T, Masukata H: Association of fission yeast Orp1 and Mcm6 proteins with chromosomal replication origins. Mol Cell Biol 1999, 19(10):7228-7236.

34. Prusty R, Grisafi P, Fink GR: The plant hormone indoleacetic acid induces invasive growth in Saccharomyces cerevisiae. Proc Natl Acad Sci USA 2004, 101(12):4153-4157.

35. Hayashi M, Katou Y, Itoh T, Tazumi A, Yamada Y, Takahashi T, Nakagawa T, Shirahige K, Masukata $\mathrm{H}$ : Genome-wide localization of pre-RC sites and identification of replication origins in fission yeast. EMBO J 2007, 26(5):1327-1339.

36. Kearsey SE, Cotterill S: Enigmatic variations: divergent modes of regulating eukaryotic DNA replication. Mol Cell 2003, 12(5):1067-1075.

37. Moreno S, Klar A, Nurse P: Molecular genetic analysis of fission yeast Schizosaccharomyces pombe. Methods Enzymol 1991, 194:795-823.

38. Forsburg SL: Introduction of DNA into S. pombe cells. Curr Protoc Mol Biol 2003, Chapter 13, Unit 1317.

39. Maundrell $K$ : Thiamine-repressible expression vectors pREP and $p R I P$ for fission yeast. Gene 1993, 123(1):127-130.

40. Hood MT, Stachow C: Transformation of Schizosaccharomyces pombe by electroporation. Nucleic Acids Res 1990, 18(3):688.

41. Sherman DA, Pasion SG, Forsburg SL: Multiple domains of fission yeast Cdc19p (MCM2) are required for its association with the core MCM complex. Mol Biol Cell 1998, 9(7):1833-1845

42. Yamada $Y$, Nakagawa T, Masukata H: A novel intermediate in initiation complex assembly for fission yeast DNA replication. Mol Biol Cell 2004, 15(8):3740-3750

43. Nakajima R, Masukata $\mathrm{H}$ : SpSId3 is required for loading and maintenance of $\mathrm{SpCdc45}$ on chromatin in DNA replication in fission yeast. Mol Biol Cell 2002, 13(5):1462-1472.
44. Woods A, Sherwin T, Sasse R, MacRae TH, Baines AJ, Gull K: Definition of individual components within the cytoskeleton of Trypanosoma brucei by a library of monoclonal antibodies. J Cell Sci 1989, 93(Pt 3):491-500.

45. Hayashi MT, Takahashi TS, Nakagawa T, Nakayama J, Masukata H: The heterochromatin protein Swi6/HP1 activates replication origins at the pericentromeric region and silent mating-type locus. Nat Cell Biol 2009, 11(3):357-362.

46. Kojima K, Niri M, Setoguchi K, Tsuda I, Tatsumi N: An automated optoelectronic reticulocyte counter. Am J Clin Pathol 1989, 92(1):57-61.

doi:10.1186/1471-2121-12-8

Cite this article as: Kanke et al:: Auxin-inducible protein depletion system in fission yeast. BMC Cell Biology 2011 12:8.

\section{Submit your next manuscript to BioMed Central and take full advantage of:}

- Convenient online submission

- Thorough peer review

- No space constraints or color figure charges

- Immediate publication on acceptance

- Inclusion in PubMed, CAS, Scopus and Google Scholar

- Research which is freely available for redistribution

Submit your manuscript at www.biomedcentral.com/submit
Biomed Central 